\title{
A EXCEÇÃo COMO Dispositivo de GOVERNO ${ }^{1}$
}

\author{
Luciano Nuzzo* \\ 1 Introdução. 2 Excepcionalismo soberano. 3 Crise. 4 A normalização da exceção. 5 \\ Soberania e biopoder. 6 Conclusão. Referências.
}

\section{RESUMO}

Por meio da discussão das ideias de Carl Schmitt e Walter Benjamin, Michel Foucault e Giorgio Agamben, este artigo visa a analisar o funcionamento de um dispositivo de governo que usa a exceção como norma. Esse dispositivo é definido como "excepcionalismo soberano" e introduz novas formas de controle, que resultam de uma combinação inédita entre excepcionalismo e governamentalidade, em que o Direito e as instituições democráticas continuam a existir, mas são sempre mais esvaziadas, revogadas por meio de práxis governamentais. O excepcionalismo soberano, em última instância, coloca-nos frente aos paradoxos do Direito e desconstrói radicalmente a geometria política moderna e a razão que constituiu seu pressuposto.

Palavras-chave: Crise. Soberania. Biopoder.

\section{INTRODUÇÃO}

O objetivo destas páginas é analisar um dispositivo de poder que faz da exceção o seu estatuto operativo. Esse dispositivo determina novas formas de relação entre Direito e Política, entre pertencimento e direitos, produzindo uma contínua redefinição do sentido dos conceitos e das categorias com as quais a Política e o Direito na modernidade haviam representado o espaço da própria operatividade. ${ }^{1-2} \mathrm{O}$ que quero fazer emergir é um quadro complexo no qual discursos, práticas e instituições constroem o que usam como objeto do próprio saber-poder. ${ }^{3}$ Nas palavras de Michel Foucault, o dispositivo representa:

Um conjunto absolutamente heterogêneo, que implica discurso, instituições, estruturas arquitetônicas, decisões regulatórias, leis, medidas administrativas com as quais se intervém nas relações para orientá-las a uma certa direção, seja para bloqueá-las ou para fixá-las e utilizá-las de modo estratégico no interior das relações de poder. ${ }^{4}$

1 Tradução do Italiano para o Português de Diego de Paiva Vasconcelos, Professor da Universidade Federal de Rondônia e doutorando na Faculdade Nacional de Direito da UFRJ. Bolsista Capes/PDSE.

* Luciano Nuzzo é "Ricercatore confermato" (pesquisador efetivo) de Filosofia do Direito e Professor Doutor de Lógica e Teoria da Argumentação Jurídica do Departamento de Ciências Jurídicas da Università del Salento. Atualmente é pesquisador visitante com uma bolsa do CNPq na Faculdade de Direito da UFRJ. E-mail: <luciano.nuzzo@unisalento.it>. 
As políticas em matéria de terrorismo e, sobretudo, as políticas em matéria de imigração que muitos países adotaram nas duas últimas décadas nos impele a compreender como os dispositivos de governo recorrem, em modo difuso, à exceção. No novo contexto histórico-político pós-colonial, da globalização, das novas guerras ao terrorismo e dos fortes fluxos migratórios que atravessam velhas e novas fronteiras, as práticas de governo excepcionais redesenham a geografia política e jurídica de um Ocidente supostamente nutrido de princípios universalistas e direitos civis. Essa centralidade do uso da exceção nas práticas governamentais reconfiguram este dispositivo e nos força a refletir sobre o Direito e a forma de organização que se costuma descrever pelo sintagma Estado Constitucional de Direito. Uma forma que aponta descontinuidade com um passado e que pressupõe um sistema institucional centrado na legitimação do poder por meio da referência à lei, ordinária e constitucional. ${ }^{5}$

Aquilo que parece emergir por meio desse dispositivo é a transformação do estado de exceção em um estado de normalidade. Em um quadro onde a regulação unitária garantida pelo Direito Público Constitucional é fraturada, assistimos a uma pluralidade de autoridades semi-soberanas, semi-constituintes, que operam nos confins da lei, no seu espaço intersticial, dentro e fora dos confins da soberania. Isso significa que a exceção funciona no interior de um processo de gestão e administração da contingência. A consequência é que a exceção não pertence mais à exceção e a norma ao direito de exceção, como predicava Carl Schmitt.

Procurando descrever o funcionamento desse dispositivo, acredito ser útil partir de um caso específico e exemplar. O campo de detenção de Guantánamo, nesse sentido, representou talvez a maior afronta às convenções internacionais do Direito, instância na qual os Estado Unidos se arrogaram um lugar fora do Direito. Ecos da espetacularização do campo podem, inclusive, ser encontrados na estética do Estado Islâmico, com seus prisioneiros vestidos de laranja. Guantánamo, assim, abriu uma discussão que, acredito, ainda não se concluiu. Embora se fale do fechamento do campo, considero que ele representa uma concretização exemplar de tal dispositivo de poder. O que interessa, ademais, não é só Guantánamo, mas o dispositivo de poder encontrável em diversos contextos, com outros nomes e outras aparências. Guantánamo torna-se o nome comum dos espaços onde o poder soberano se exerce do lado de fora dos limites do estado de Direito e das convenções de Direito Internacional como uma prática governamental. A guerra passar a ser um caso de polícia.

Não é um acaso que a triste história de Guantánamo, como lugar de internamento e legal black hole, como espaço de exceção e de produção de novas formas de aniquilamento da subjetividade, tenha sido iniciada com a autorização concedida pelo Congresso ao então Presidente George W. Bush, após o ataque terrorista às torres gêmeas em Nova Iorque. Nela, se reconheceu o direito do Presidente de utilizar:

all necessary and appropriate force against those nations, organizations, or persons he determines planned, authorized, committed, or aided the terrorist attacks that occurred on September 11, 2001, or harboured such organizations or persons, in order to prevent any future acts of international terrorism against the United States by such 
nations, organizations or persons (Authorization for Use of Military Force, Pub. L. N. 107-40, 115 Stat. 224, 2001) ${ }^{6}$

Graças aos poderes conferidos pelo Congresso com esta decisão, Bush, mesmo antes de lançar mão das operações militares anglo-americanas contra o Afeganistão talibã, promulgou uma ordenação militar sobre a detecção, detenção e tratamento dispensados àqueles capturados durante a guerra ao terrorismo. Lembrar a Authorization for Use of Military Force torna imediatamente perceptível a excepcionalidade de Guantánamo e permite evocar o debate teórico jurídico sobre o significado de uma detenção infinita subtraída da lei e do controle judiciário, mas que, ainda assim, afırma aplicar a lei e tem a necessidade de utilizar o processo como meio de comunicação para com um público mundial. ${ }^{7}$

O campo cubano é, para o observador que observa utilizando a distinção Direito/não Direito, um vácuo que permite superar a diferença entre soberania e governamentalidade, entre lei e ato administrativo, entre nacional e estrangeiro. O campo é o início de uma nova ordem jurídica, invisível começo de um novo sistema social que, por meio de um impulso externo ao Direito, como sistema constitucionalmente garantido, se mostra apto a anular o estatuto jurídico do indivíduo, produzindo um ser juridicamente inominável e inclassificável. ${ }^{8-9}$

A violência absoluta, espetacular e terrível do ataque às torres gêmeas de Nova York é, de fato, o big bang na origem da Declaration of National Emergency by Reason of Certain Terroristic Attacks (14.11.2001), uma situação de emergência que permitiu ao Presidente dos Estados Unidos superar a rígida separação de poderes sob a qual se funda o arranjo constitucional americano e de promulgar o Patriot Act, o President Issues Military Order, as Ordenações e Instruções para a Comissão Militar, instâncias em que se atribuiu competência para julgar os suspeitos de atividade terrorista ou de atividade contrária aos interesses nacionais.

\section{EXCEPCIONALISMO SOBERANO}

Não é necessário fazer referência ao discurso de George W. Bush ao Congresso ou às diretrizes de governo em matéria de antiterrorismo. Basta ler a página política de um jornal ou ouvir um debate na televisão para se deparar com a afirmação de que tempos de exceção demandam medidas excepcionais. Em outras palavras, a excepcionalidade dos eventos, diz-se, causou uma situação nova, não previsível e que necessita de uma resposta, por sua vez, excepcional. Trata-se de afirmações que pertencem ao senso comum. Entretanto, o senso comum, como lembra Wittgenstein no seu ensaio "Da certeza", não é comum porque se funda sobre dados comumente aceitos, percebidos por todos da mesma maneira. $\mathrm{O}$ senso comum não tem nada de natural. Trata-se da generalização de determinados esquemas cognitivos. Portanto, embora o senso comum não seja saber científico, mantém uma relação muito estreita com este, em um duplo sentido: porque tem uma estrutura gramático-teórica imanente e porque generaliza esse esquema de tal modo que possa parecer natural. ${ }^{10}$ Assim, 
para procurar compreender a afirmação sobre "tempos excepcionais produzirem e demandarem medidas excepcionais” é necessário se aprofundar no significado da relação exceção/ excepcionalismo. Desse modo, pode-se ver que aquilo que aparenta ser uma obviedade é, ao invés, uma afirmação que pressupõe implicitamente uma determinada concepção da realidade e assim uma determinada teoria do conhecimento e, sobretudo, uma determinada posição nos confrontos da Política e do Direito.

Embora não se possa, nesse artigo, deter-se sobre as implicações epistemológicas da citada expressão, emerge, de modo imediato, o modo como se postula uma relação linear do tipo causa/efeito entre exceção e excepcionalismo. O evento excepcional como tal é inacessível. O caráter excepcional do evento depende de um observador que o constrói como tal. Depende, em outros termos, de ser interpretado e representado como excepcional. Depende, em última análise, da utilização de uma distinção entre normal e excepcional que permite construir o mundo com tal distinção e qualificar um evento como excepcional. ${ }^{11}$

A utilização da distinção entre regra e exceção é rica em implicações. Na verdade, a construção e a representação de uma situação como emergência/exceção constitui, num primeiro momento, a condição de operatividade de um novo dispositivo de poder. A representação da exceção antecipa o próprio evento, produzindo e determinando consequências excepcionais. A exceção não é uma situação real, objetiva, depende do poder de declará-la como tal. Isso significa que o evento é o resultado de uma construção, depende da sua representação.

Não é de espantar que um dos mais profundos teóricos da soberania, Carl Schmitt, não tenha fugido do problema posto pela exceção. Toda a sua teoria da soberania, na verdade, gira em torno da questão da decisão como prerrogativa do soberano, não sendo limitada pela lei. Quem decide sobre o estado de exceção, diz Schmitt, "decide tanto sobre se existe um caso extremo de emergência, quanto sobre o que se deve fazer para superá-la."12

Resulta, então, evidente que declarar um evento como excepcional torna-se o instrumento para produzir e legitimar as medidas realmente excepcionais. Desse ponto de vista Guantánamo é um caso paradigmático. É o produto de um conjunto de discursos e práticas que se configuram como excepcionais em relação às regras do Direito Internacional, tanto quanto em relação às do Estado de Direito Constitucional. Constitui-se como resultado daquele dispositivo de saber/poder definido como excepcionalismo soberano. A relação que instaura com a exceção é dupla. Em primeiro lugar, porque a colocação do campo na base militar de Guantánamo teve o intuito de evitar que aos prisioneiros se pudessem aplicar as normas previstas no Direito estadunidense. Colocar o campo na base militar, sob a jurisdição do exército americano, garantiu que os prisioneiros fossem postos fora do alcance legal, exclusivamente à mercê do que Derrida chamou de "a força de lei sem lei." 13 Em segundo lugar, o fato de os supostos terroristas serem detidos em uma base militar estadunidense e, assim, em um lugar não secreto, constituía uma afirmação de soberania. ${ }^{14}$ 
Mas não se trata apenas disso. Por meio da constituição, da gestão e da difusão do modelo Guantánamo, torna-se explícita e, portanto, visível uma forma de poder governamental cujo objetivo é a gestão, a submissão e o controle de indivíduos e populações previamente constituídos como perigosos. Em outros termos, Guantánamo realiza uma mudança significativa das estratégias de segurança e de defesa em relação à prevenção. Os exemplos são inúmeros, o ponto central, entretanto, independentemente do caso específico, é que a decisão sobre a periculosidade é confiada à via preventiva dos aparatos militares ou de polícia e perde seu caráter provisório. As medidas de polícia se autonomizam da magistratura/Judiciário. No interior de um quadro político caracterizado por um fortalecimento do Executivo perante órgãos eletivos e da administração sobre a jurisdição, assiste-se, em muitos casos, a um deslocamento das prerrogativas - e até mesmo dos direitos - do Judiciário à força do poder da polícia. Esse deslocamento responde a uma lógica discursiva imanente ao dispositivo do excepcionalismo soberano. O discurso sobre a "guerra ao terrorismo" funciona como produção e legitimação da exceção.

As novas leis sobre terrorismo e, em geral, a política de segurança introduzem novas formas de controle, como os centros de identificação e expulsão de migrantes irregulares ou aqueles de identificação para os que requerem asilo, novos procedimentos revogatórios das regras ordinárias de Direito Penal e, em alguns casos, como naqueles dos prisioneiros de Guantánamo, jurisdição especial. Em todos esses casos, como na situação dos prisioneiros de Guantánamo julgados por comissões militares ad hoc, o papel do Judiciário parece absolutamente residual ou, no mínimo, subalterno em relação ao aparato militar ou da polícia.

\section{CRISE}

A representação de um evento como excepcional produz a exceção, isso é, produz a decisão sobre o estado de exceção. Carl Schmitt põe em evidência, de maneira politicamente interessada, o caráter político da decisão. O fato é que a distinção imanente ao político é aquela entre amigo e inimigo. ${ }^{15} \mathrm{~A}$ decisão política última, em outras palavras, é sempre expressão de uma crise. A etimologia da palavra crise (Krisis), sob este ponto de vista, é particularmente significativa. Como explicou Koselleck, Krinai indica o momento extremo, a última fase de uma doença, quando há a luta entre vida e morte. ${ }^{16}$ Se escavássemos as sedimentações de sentido da palavra, encontraremos o juízo, a decisão, o risco terrível da escolha. Como observou Eligio Resta, o discurso sobre a exceção é o discurso típico das crises e significa redescobrir uma dimensão política do Direito, uma dimensão na qual a distinção que opera é aquela entre amigos/inimigos. ${ }^{17}$

O problema é a decisão. E a decisão que decide sobre o estado de exceção, como mais uma vez disse Schmitt, é uma decisão absoluta cuja validade depende da sua legitimidade de ser a decisão de autoridade constituída. E, consequentemente, a legitimidade da autoridade consiste no fato de que toma a decisão. Instaura-se uma relação circular entre decisão, evento 
excepcional e legitimação das práticas excepcionais que dela derivam. A decisão antecipa o evento. A representação do evento como excepcional funciona como legitimação das práticas excepcionais. Aquilo que emerge do estado de exceção funciona como legitimação de práticas excepcionais. O que emerge é o caráter belicoso da Política: a construção do outro como inimigo e a legitimação de medidas que limitam o Direito e direitos. Penso, contudo, que uma crítica do estado de exceção não se possa limitar a colocar em evidência o aspecto, embora de fundamental importância, das limitações e privações do Direito e dos direitos. É necessário, como alerto, enfrentar toda ambivalência e paradoxalidade do estado de exceção para ver e indagar a relação estrutural entre Direito e violência.

A teoria do estado de exceção permite desconstruir essas representações que neutralizaram o político no interior da relação jurídica, de um lado, e, de outro, no interior do liberalismo econômico. $\mathrm{O}$ estado de exceção é um conceito limite que permite observar o paradoxo de que a autoridade não necessita do Direito para criar direito. $O$ Direito no estado de exceção denuncia sua origem, isto é, o fato de não haver direito de ser Direito; denuncia sua relação constante com a violência que o funda e conserva. Mas a decisão para poder decidir deve poder operar a distinção entre Direito e não Direito, entre regra e exceção. Se é verdade que a relação entre norma e exceção se inverte, ou seja, a exceção passa ser a condição para aplicação da norma, a distinção entre eles deve permanecer. $\mathrm{O}$ estado de exceção, no momento em que libera e denuncia a violência que funda o Direito, paradoxalmente, mantém aberta e constante a relação entre Direito e violência. $\mathrm{O}$ estado de exceção é, portanto, o mecanismo por meio do qual a exceção, no seu significado etimológico, ex capere, inclui aquilo que lhe é estranho. O Direito, por meio do ciclo violência-Direito-violência, que para Benjamin constitui o núcleo mítico, retorna à sua origem. Reativa a memória da sua origem e, por meio da construção da própria história, oculta o seu paradoxo constitutivo. Desse modo, pode produzir a própria imunização. Pode, em outros termos, operar distinguindo o Direito do não Direito. Em outras palavras, apenas o contínuo retorno do passado pode salvar o presente da incerteza que o futuro projeta. A imunização do Direito em relação à Política pode se realizar, assim, para Schmitt, por meio do estado de exceção, que garante a segurança nos confrontos de um risco futuro por meio de doses preventivas sustentáveis. ${ }^{18}$

\section{A NORMALIZAÇÃO DA EXCEÇÃO}

Qual é o preço que se paga por esta imunização? Trata-se de uma real imunização? Isto é, uma vez que o Direito se confunde com a Política - e substitui seu próprio código por aquele de amigo/inimigo -, de que modo pode operar?

Schmitt disse que para salvar a constituição é necessário suspendê-la. Porque a norma para ser aplicada necessita de uma ordem. E no estado de exceção há uma fratura do sintagma do ordenamento jurídico. O mérito de Schmitt é o de possibilitar ver o paradoxo do Direito moderno na sua relação constante com a violência e a exceção. A exceção representa uma 
possibilidade imanente ao jurídico e não um acidente no curso de sua história. E este é um ponto decisivo. Mas, para Schmitt, o problema é remover a exceção. E o estado de exceção é o dispositivo por meio do qual a anomia é recolocada no interior do ordenamento. $\mathrm{O}$ problema, contudo, persiste porque o estado de exceção, uma vez introduzido, comporta uma radical transformação do próprio ordenamento. Ele esconde em seu interior uma lógica mimética. Direito e violência apoiam-se em sua indissolúvel unidade. Mas isso significa que o Direito não pode mais operar com um código diferente daquele amigo/inimigo. No momento, portanto, no qual o Direito denuncia a sua origem e não consegue distinguir-se e diferenciar-se do político, perde a diferença e, assim, assemelha-se à guerra. $O$ Direito Penal assume, então, o risco de transformar-se em "Direito do inimigo". Um Direito que não estabiliza expectativas, mas que aumenta a possibilidade de frustração, generalizando os fatores de insegurança. Um Direito que assume diretamente uma tarefa política de defesa contra um inimigo.

O que emerge, então, das políticas de segurança é uma inversão da relação regra/exceção. No sentido que a exceção se normaliza, tornando-se modalidade estável de gestão da Política e do Direito. Isso significa que a exceção, uma vez introduzida, se normaliza. Não constitui um intermezzo para a (re)estabilização da ordem, mas, antes, torna-se instrumento para organizar e legitimar uma nova ordem.

A questão que se coloca aqui é para onde conduz a teoria do estado de exceção de Schmitt. A tal propósito é oportuno retomar a discussão entre Schmitt e Walter Benjamin sobre a normalidade do estado de exceção. Não estranha, de fato, que Schmitt e Benjamin, dois autores tão diversos sob todos os aspectos, compartilhassem desde perspectivas opostas, durante os anos convulsos da República de Weimar, o juízo negativo sobre a democracia liberal e, mais amplamente, uma crítica à confiança otimista e cega no progresso nas duas versões que surgiram entre os séculos XIX e XX: a liberal e a social-democrática. Como observou Norbert Bolz, Benjamin se interessou por Schmitt por causa da analogia fisionômica entre a crítica reacionária e anárquica, vendo em ambos os casos uma recusa dos mitos liberais e a afirmação do estado de exceção como o elemento central da ordem política. ${ }^{19-20}$

No ensaio de 1921, "Para a crítica da violência", Benjamin afirma que o escândalo que a violência constitui, quando observada pela perspectiva do Direito, é estar fora do Direito. O Direito não pode tolerar a existência de um fora, deve excluir o fora que é a violência, e tal exclusão não pode acontecer se não por meio de uma inclusão, uma interiorização do que é externo. A ilegitimidade da violência consiste na sua posição e não no seu conteúdo. Ela persistirá enquanto a violência permanecer externa ao Direito. O Direito posto pela violência a reconduz ao seu interior, mas no momento em que o Direito produz tal interiorização, o Direito mantém a diferença com a violência. Assim o Direito moderno, no uso da violência legítima, pode reproduzir e repetir a sua origem. ${ }^{21-22}$ À diferença de Schmitt, que quer neutralizar a violência recolocando-a no interior do Direito, Benjamin quer afirmar a 
realidade de uma violência pura, a violência revolucionária. Esta é uma violência externa e estranha ao Direito: "O caráter próprio dessa violência é que ela não põe nem conserva o direito, mas o depõe e inaugura, assim, uma nova época histórica.”23

Em A Ditadura, Schmitt usa a distinção entre o poder constituinte e o poder constituído, entre norma de lei e norma de atuação, a fim de distinguir entre a ditadura comissária, na qual o exercício do poder além da lei se justifica para a conservação da lei e do estado, e a ditadura soberana, na qual o exercício da violência sem Direito è usada para instaurar uma nova ordem jurídica. Na República de Weimer, a referência schmittiana à ditadura comissária, portanto, significava, por um lado, invocar e justificar um governo forte, não mais vinculado a um parlamento incapaz de enfrentar a crise econômica e política deflagrada pelo tratado de Versalles; por outro lado, significava manter uma relação entre violência e Direito. ${ }^{24}$

Para Benjamin, por sua vez, trata-se de desconstruir a teoria schmittiana do estado de exceção e pensar uma violência que não tem nenhuma relação com o Direito, uma violência pura que não esteja em uma relação de meio-fins com o Direito. E, portanto, uma violência que seja puro meio e, como tal, nem põe nem conserva o Direito. Como observa Giorgio Agamben: "a violência pura expõe e corta o elo entre direito e violência e pode, assim, aparecer ao final não como violência que governa ou executa mas como violência que simplesmente age e se manifesta." ${ }^{25}$ Assim, a teoria schmittiana do estado de exceção pode ser lida como uma tentativa de responder à crítica de Benjamin. $\mathrm{O}$ estado de exceção torna-se um dispositivo que permite reconduzir ao interior do Direito o que é estranho ao Direito. Ao mesmo tempo, a impossibilidade de decidir juridicamente o caso de exceção funda a necessidade da decisão do soberano como "suprema potestas superiorem non recognoscens" (Bodin). Para Schmitt, a dimensão absoluta da decisão aparece, precisamente, no estado de exceção.

Em "O Drama Barroco", Benjamin retoma as categorias de Schmitt de soberania, decisão, estado de exceção, mas coloca-as em um horizonte completamente diferente que lhes altera radicalmente o sentido. A idade barroca, para Benjamin, é dominada pela crise. As personagens que a povoam são caracterizadas pela percepção de uma catástrofe iminente. O príncipe da alegoria barroca é incapaz de tomar decisão, apesar de ser o titular do poder supremo. As situações nas quais é constantemente envolvido demonstram, para Benjamin, essa incapacidade. A soberania é vazia, é um simulacro. O soberano, como observa Agamben, é "o lugar em que a fratura que divide o corpo do direito se torna irrecuperável: entre Macht e Vermoegen, entre o poder e seu exercício, abre-se uma distância que nenhuma decisão é capaz de preencher."26

A catástrofe, portanto, e não o milagre, constitui, para Benjamin, diferentemente de Schmitt, o paradigma do estado de exceção. Mas se o estado de exceção é, de acordo com Schmitt, o lugar no qual se articula a relação entre anomia e contexto jurídico, para Benjamin, o estado de exceção é, como escreve Agamben, "antes, uma zona de absoluta indeterminação entre anomia e direito, em que a esfera da criação e a ordem jurídica são arrastadas em 
uma mesma catástrofe." ${ }^{27}$ A tentativa do poder estatal de anexar (a si mesmo) a anomia por meio do estado de exceção é uma representação que tem como fim desvincular o poder da lei, mantendo a lei em um estado de vigência sem aplicação. Benjamin, na sua crítica a Schmitt e à concepção do Direito como violência, denuncia o caráter fictício do estado de exceção, o seu ser uma construção do direito violento e da violência jurídica. Contrariamente a Schmitt, Benjamin chega a uma posição radicalmente anti-estatal. O ponto central que emerge da análise de Benjamin é que a verdade da história não reside na lei, na regra, na norma, mas na violência de uma soberania que se afirma no limite, no estado de exceção que traz à luz a nudeza da relação política como relação bélica. ${ }^{28}$

Em 1934, na abertura de seu ensaio "Staat, Bewegung,Volk", Schmitt escreve:

A constituição de Weimar não está mais em vigor. Depois da lei de 24 de março de 1933 (Gesetz zur Behebung der Not von Staat und Volk) sobre os plenos poderes, cada tentativa de justificar ou de refutar a situação jurídica atual em base a Constituição de Weimar é vista pelo estado nacional-socialista como um jogo sem sentido; ou então, como uma expressão da tendência política de reconduzir o direito público hoje válido e a auctoritas rei constitutae, que pertence ao estado atual, a ordens jurídicas superadas e, assim, paralizá-lo ou, pelo menos, relativizá-lo. ${ }^{29}$

Em 1933, entrava-se em um regime transitório cujo resultado imediato não era outro senão o estado total. $\mathrm{O}$ estado totalitário era, no entanto, pensado e repensado como consequência inevitável da crise do estado de direito, como um estado de justiça irredutível a um formalismo legislativo vazio, como o produto constitucional da exceção e conjuntamente como agente de transformação de exceção em regra. A crítica de Benjamin havia acertado o ponto.

Em 1940, frente à realidade do estado de exceção, Benjamin retoma as categorias de Schmitt para desmascarar seu caráter reacionário. No último e profético texto de Benjamin, "Sobre o conceito de História", na tese VIII, lê-se: "A tradição dos oprimidos ensina-nos que o estado de exceção em que vivemos é a regra." ${ }^{30}$ Diante da indeterminação entre exceção e regra que se realiza no Terceiro Reich e na Europa dos totalitarismos, Benjamin afirma que a distinção entre violência e Direito torna-se impossível e o estado de exceção, no momento em que se normaliza, se transforma em uma fictio iuris. Aquilo que resta é um vazio, um lugar no qual violência e Direito são indistinguíveis.

Ainda na tese VIII, lê-se:

Temos de chegar a um conceito de história que corresponda a essa ideia. Só então se perfilará diante dos nossos olhos, como nossa tarefa, a necessidade de provocar o verdadeiro estado de exceção; e assim a nossa posição na luta contra o fascismo melhorará. A hipótese de ele se afirmar reside em grande parte no fato de os seus opositores o verem como uma norma histórica, em nome do progresso. O espanto por as coisas a que assistimos "ainda" poderem ser assim no século vinte não é um espanto filosófico. Ele não esta no início de um processo de conhecimento, a não ser o de que a ideia de história de onde provém não é sustentável. ${ }^{31}$ 
Reconhecer que o estado de exceção seja a regra significa repensar as modalidades de luta contra o fascismo. Significa substituir a ideia de história como tempo linear e infinito pela imagem paradoxal de um estado da história, no qual o evento fundamental é sempre em curso e a meta não está longe, no futuro, mas é sempre já presente. ${ }^{32}$ A revolução de Benjamin quebra a concepção reacionária de Schmitt e aparece paradoxalmente no momento da catástrofe, como o tempo cairológico no qual o homem aproveita a oportunidade e decide no átimo da própria liberdade. ${ }^{33}$

\section{SOBERANIA E BIOPODER}

A nossa época se caracteriza por uma normalização do estado de exceção. O estado de exceção não precisa mais ser declarado formalmente, opera como produção e representação discursiva de uma situação de fato que permite um exercício extralegal de poder em nome de exigências governamentais. No momento em que o estado de exceção se transforma em regra, o espaço que se abre é um espaço que não conhece pacificação; é, então, um espaço onde a Política, de acordo com Foucault, se manifesta como prossecução da guerra com outros meios, invertendo a fórmula de Claussewitz. ${ }^{34}$

O inimigo é criminalizado, e a guerra se transforma em uma operação de polícia permanente, cuja finalidade não é derrotar o inimigo identificável, mas a gestão da insegurança. E isso significa que o dispositivo da guerra e do estado de exceção se normalizam. Práticas excepcionais saem do interior do estado de exceção, no qual eram ocultadas, para retornarem, na sua complexidade, ao "espaço político da cidade". A Política torna-se indistinguível da polícia. E a polícia, como na intuição de Benjamin, torna-se soberana.

Hannah Arendt, em uma passagem a propósito da situação dos apátridas, escreve:

Foi essa a primeira vez em que a polícia da Europa ocidental recebeu autoridade para agir por conta própria, para governar diretamente as pessoas; nessa esfera da vida pública, já não era um instrumento para executar e fazer cumprir a lei, mas havia se tornado autoridade governante independente de governos e de ministérios. $^{35}$

É interessante notar que esta observação é proposta pela filósofa num capítulo em que analisa a crise de categorias políticas modernas que construíram o espaço da Política e o Direito em torno da tríade território, ordenamento e nação. A questão que se coloca aqui é como se conjugam o excepcionalismo e o poder de governo enquanto biopoder. Em outras palavras, como se relacionam o poder soberano sobre a vida e a morte e uma tecnologia política cujo objetivo é organizar e potencializar a vida individual ou de uma população?

Na última lição do curso de 1976 no College de France, Foucault interroga-se sobre o caráter biopolítico do regime nazista: "se é verdade que o fim (do Estado) é essencialmente aquele de potencializar a vida, como é possível que um poder político mate, reivindique a 
morte, exija a morte, dê a ordem de matar, exponha à morte não somente os seus inimigos mas também os seus cidadãos?"36

O poder que é desenvolvido a partir do século XVIII se caracteriza por ser um poder sobre a vida, isto é, se exercita sobre a vida do homem enquanto ser vivente. A velha ideia de um Direito soberano de vida e de morte, um Direito assimétrico que define a vida em relação à morte, é substituída por um poder de viver e repelir a morte. Ora, isso não significa menos direito de morte, mas sua adaptação à exigência de um poder que administra a vida. A guerra não é feita em nome da defesa do soberano, mas em nome da existência de todos. $\mathrm{O}$ poder de morte que se manifesta na guerra se apresenta como o complemento daquele que se exercita sobre a vida. Nesse sentido, o racismo moderno representa o modo pelo qual se introduz uma censura no domínio da vida. Uma censura entre o que deve viver e o que deve morrer.

O racismo de estado determina o modo de continuação e transformação da guerra. Os inimigos não são adversários políticos. São elementos potencialmente mais perigosos ainda, externos ou internos à população. $\mathrm{O}$ discurso sobre a cidadania funciona como legitimação dos dispositivos de exclusão e de expulsão da comunidade. O status de cidadão não indica a posição jurídico-formal de um sujeito face ao ordenamento jurídico, mas vem carregado de um significado diretamente político-existencial, ou, se preferir, biopolítico. Ser cidadão torna-se condição essencial para não ser privado das condições materiais de existência. De modo análogo, também a outra parte da distinção, o não-cidadão, se preenche de novos conteúdos. Ser não-cidadão é o sinal biológico do não pertencimento a uma determinada população. Assim, é possível a identificação do inimigo enquanto ameaça à sobrevivência da população a que não pertence.

O paradoxo biopolítico de Foucault, no entanto, não obstante a análise do racismo como dispositivo que reintroduz a morte no biopoder, é destinado a não ser resolvido. Na verdade, o racismo explica a função da morte no interior do biopoder, mas não o poder do soberano de decidir sobre o valor e o desvalor da vida. O problema é, mais uma vez, a soberania que retorna porque, como recorda Bataille, "a missa fúnebre do rei é a maior afirmação da soberania." 37

Agamben, por meio de um diálogo travado com Schmitt e Benjamin e com Arendt e Foucault, pensa o poder a partir da conexão entre soberania e biopoder. O que para Foucault representa um problema insolúvel, a relação entre soberania e biopolítica e entre liberalismo e totalitarismo, é superado na perspectiva de Agambem, que pensa o campo como espaço no qual a soberania e o biopoder se entrelaçam e no qual o liberalismo se inverte em totalitarismo. No momento em que o nazismo realiza os dispositivos já presentes no regime liberal e quando o poder soberano reaparece sob a forma de racismo de estado, a forma de uma decisão sobre a vida e a morte baseada em uma razão biológica, fica evidente como Política e vida aparecem estreitamente ligadas desde o início da modernidade e como o poder se 
exprime em um controle e um assujeitamento total da vida. No estado de exceção, tornado para Agamben permanente, a decisão soberana sobre a exceção consiste em dispor da vida, no seu poder essencial de suspendê-la, colocando-a numa zona de indiscernibilidade entre vida e morte. ${ }^{38}{ }_{-} 39$

Na teoria de Schmitt da soberania como decisão sobre o estado de exceção, de acordo com o filósofo italiano, é possível reconhecer o nó biopolítico no qual a soberania comprime a vida. Por meio da antiga figura do direito romano arcaico do homo sacer, Agamben reconstrói o percurso que leva ao biopoder: "Colocando a vida biológica no centro de seus cálculos, o Estado moderno não faz mais, portanto do que reconduzir à luz o vínculo secreto que une o poder à vida nua." 40 A condição do homo sacer de ser passível de morte mas não de sacrifício, representa, como a exceção soberana, uma condição limite. Soberano e vida nua estão nos pólos opostos de uma relação de exclusão recíproca. Soberano é aquele diante do qual todos os homens são sacer, matáveis sem que se cometa homicídio, porque o soberano está, ao mesmo tempo, fora e dentro da ordem. Por outro lado, homo sacer é aquele diante do qual todos os homens são soberanos, podem matá-lo sem cometer homicídio. Soberano e homo sacer, limites extremos da ordem, colocam em discussão os confins. Em ambos os casos se percorre uma zona de indistinção entre interno e externo. O homo sacer vive, como o soberano, na exceção, em um estado no qual violência e Direito, fato e norma se indeterminam, no qual os confins entre lícito e ilícito se confundem. A soberania é, portanto, "a estrutura originária na qual o direito se refere à vida e a inclui em si através da própria suspensão." ${ }^{1}$ No momento em que o nazismo leva às últimas consequências a decisão soberana sobre o valor e o desvalor da vida, o campo não pode mais ser considerado uma anomalia pertencente ao passado, um fato histórico, mas o nomos do espaço político moderno. ${ }^{42}$

Os campos, então, que se difundem no interior e no exterior das fronteiras dos estados, para internar os inimigos de "guerras infinitas", ou para construir barreiras contra os migrantes, representam o ponto mais visível de um processo que tem como objetivo a gestão das formas de vida por meio de uma reconfiguração nas chaves de segurança do espaço da Política. O campo constitui o "não lugar" da Política no momento em que a geometria política da modernidade entra em crise. Indica o espaço no qual o poder soberano se exercita, livre de vínculos, em toda a sua força e no qual o político se manifesta sem mediação do jurídico no confronto com um indivíduo que, desprendido de vínculos de pertencimento e de direitos, sem cidade e sem cidadania, surge frente ao poder exclusivamente como vida nua, como zoe e não mais como bios. O campo, como as figuras que o habitam, é um limite da Política e do Direito, isto é, onde se redefinem as relações entre violência e Direito, entre pertencimento e Direito. Onde a Política e o Direito assumem a vida na sua totalidade até confundirem-se com ela. O campo é o espaço no qual o poder soberano opera como mecanismo de produção e transformação da vida natural em vida nua. 


\section{CONCLUSÃO}

O dispositivo definido como excepcionalismo soberano encontra no campo o seu lugar paradigmático. De acordo com Agamben, o campo é uma localização do estado de exceção. É a estrutura na qual o estado de exceção, cuja possibilidade de existência funda o poder soberano, se realiza normalmente. O espaço do campo, território separado da comunidade, se põe fora da ordem. Isso pressupõe uma separação entre Ortung e Ordunung, entre Localization e Order. É uma localização sem ordem. Mas, ao mesmo tempo, mantém uma relação com a ordem $^{43}$. Disso deriva que no espaço do campo se realiza, em última instância, uma confusão entre Direito e fato, entre violência e Direito, entre norma e aplicação. O Direito não pode mais operar como Direito. Portanto, quem entra no campo vive o estado de exceção, uma situação "de indistinção entre externo e interno, lícito e ilícito, na qual cada proteção jurídica é reduzida, no qual a polícia tem um poder absoluto e indiscutível de decisão." ${ }^{44}$

O campo também integra o mais absoluto espaço biopolítico, sendo os seus habitantes espoliados de cada estatuto político e reduzidos à vida nua. ${ }^{45}$ Para Agamben, o campo representa o horizonte extremo das práticas governamentais do poder estatal, o lugar no qual a soberania da lei, fundada sobre a sanção e sobre a responsabilidade subjetiva, se confunde e se dissolve em prática de controle, que assume como próprio objeto não indivíduos, mas membros de categorias nacionais, raciais ou sociais percebidos preventivamente como suspeitos ou danosos por definição; ${ }^{46}$ e nesse sentido parece claro como a função do campo não é aquela de punir quem cometeu um delito, mas a de isolar a título preventivo uma parte do corpo social sobre a base de uma presunção de periculosidade. Uma estrutura com o fim não de punição e reeducação de um sujeito culpado, mas de controle de uma população que, por dadas características e condições, é considerada perigosa e, por esta razão, é presa, capturada no interior de uma relação de bando, fechada no interior de um espaço de confinamento no qual a administração é liberada da lei para exercer completamente sua vocação governamental.

Excepcionalismo soberano é um dispositivo, isto é, uma rede de conexões entre saber, poder, instituições, que intervém sobre a vida, moldando corpos e produzindo sujeitos. De um lado, a condição de seu operar é a emergência; por meio da decisão, se produzem, estabilizam e legitimam práticas de controle excepcionais. De outro, o excepcionalismo soberano tende a estabilizar a exceção, a transformar por meio da legitimação de novas práticas a exceção como práxis para o exercício de governo. O exercício extralegal do poder estatal justifica a si mesmo por tempo indeterminado, colocando-se como fator mais ou menos permanente na vida política. Tal dispositivo introduz novas formas de controle, que resultam de uma combinação inédita de excepcionalismo e governamentalidade e na qual o direito e as instituições democráticas continuam a existir, mas são sempre mais esvaziadas, revogadas por meio de práxis governamentais.

Mas, sobretudo, o dispositivo excepcionalismo soberano nos coloca frente aos paradoxos do direito e desconstrói radicalmente a geometria política moderna e a razão que constituiu 
seu pressuposto. As categorias com as quais a Política moderna construía o espaço a partir da distinção entre interno/externo, entre polícia/guerra, regra/exceção, criminoso/inimigo permitiram criar representações políticas estáveis, garantindo ao direito diferenciar-se da política e da religião e, ao mesmo tempo, imunizar-se da violência. A violência, excluída da comunicação por meio da sua inclusão na forma de desvio, constituía o pressuposto ausente do poder. $O$ Direito pôde operar apenas ocultando o seu paradoxo constitutivo, o fato de não ter direito a ser Direito. À condição de ocultar a latência, o Direito moderno podia utilizar operativamente a distinção entre Direito e não Direito e, ao mesmo tempo, podia construir sua própria história de inclusão e reconhecimento. Nada mais que um relato entre tantos possíveis na quais o Direito se narra, se põe em frente a si mesmo e não vê nada além de si mesmo. ${ }^{47-48} \mathrm{O}$ dispositivo excepcionalismo soberano configura-se como o espaço de um Direito que não é Direito, de uma exclusão que não dialoga mais com a inclusão, de uma violência sem logos. $\mathrm{O}$ sistema jurídico revela de modo catastrófico as próprias latências. Aquilo que aparece é o paradoxo do Direito, a forma de uma ausência de formas, a face de um mundo sem face. ${ }^{49}$

Como vimos, esse dispositivo opera por meio da crise: ele depende da crise para existir e a (re) produz, uma vez que funciona precisamente na zona de confinamento e de indeterminação que se abre quando as categorias da política moderna são postas em xeque pela nova ordem econômica e política. E se é verdade que tais momentos e espaços eram presentes e necessários como pressupostos para o normal funcionamento da Política e do estado, eles, ao mesmo tempo, foram construídos como excepcionais. Quando, ao invés, os confins que o constitucionalismo liberal procurou estabelecer entre Política e Direito desvanecem e inclusão e exclusão se indeterminam, aquilo que era confinado ao privado, ao oikos, torna-se objeto privilegiado de intervenção pública. Todo o espaço político aparece então como espaço de exceção onde as formas de legitimação de poder por meio do direito e seus procedimentos são indefinidamente suspensos e onde vigora "uma força de lei sem lei." 50

O excepcionalismo soberano, finalmente, coloca-nos frente a uma transformação do funcionamento do Direito contemporâneo. Este não mais parece ser estruturado sobre a soberania da lei, mas é cada vez mais determinado pela racionalidade técnica que pode existir sem a mediação política pensada pela tradição jurídica moderna. O Direito não estabiliza mais as expectativas, mas se orienta cada vez mais às próprias consequências, tornando-se um conjunto de técnicas de gestão do risco. As formas de legitimação das decisões, ademais, de transformam radicalmente. Se no estado constitucional de direito a decisão é legitimada por meio dos procedimentos com os quais se forma, agora a decisão se impõe na contingência de uma situação de crise. A legitimação não vem ex ante, mas somente ex post. A legitimidade da decisão depende do sucesso da intervenção que ela produz. 


\section{REFERÊNCIAS}

AGAMBEN, G. Homo Sacer: o poder soberano e a vida nua. Belo Horizonte: Editora UFMG, 2007.

. Che cosa è un campo. In: . Mezzi senza fine. Torino: Bollati Boringhieri, 1996. p. 35-45. 2001.

. Infanzia e storia: distruzione dell'esperienza e origine della storia. Torino: Einaudi, . Estado de exceção: homo sacer, II. São Paolo: Boitempo, 2004.

. Che cosa è un dispositivo. Roma: Nottetempo, 2006.

ARENDT, H. Origens do totalitarismo. São Paolo: Companhia de Bolso, 2015.

BATAILLE, G. La sovranità. Bologna: Il Mulino, 1990.

BENJAMIN, W. Sobre o conceito da historia. In: BENJAMIN, Walter. O anjo da historia. Rio de Janeiro: Autentica, 2012. p. 9-20.

. Sobre a critica do poder como violência. In: BENJAMIN, Walter. O anjo da historia. Rio de janeiro: Autentica, 2012. p. 57-82.

. Il dramma barocco tedesco. Torino: Einaudi, 1999.

BOLZ, N. Charisma und Souveranität: Carl Schmitt und Walter Benjamin im Schatten Max Webers. In: TAUBES, Jacob. Religionstheorie und Politische Teologie: Der Fürst dieser Welt - Carl Schmitt und die Folgen. München: Fink, 1983. v. 1. p. 254-257.

BUCI-GLUCKSMANN, C. H. Walter Benjamin et l'ange de l'histoire: une archéologie de la modernité. L'Ecrit du Temps 2, n. 2, p. 45-85, 1983.

BUTLER, J. Precaroius life: the powers of mourning and violence. London: Verso, 2004.

DAL LAGO, A. Polizia globale. Guerra e conflitti dopo l'11 settembre. Verona: Ombre Corte, 2003.

DERRIDA, J. Forza di legge: il fondamento mistico dell'autorità. Torino: Bollati Boringhieri, 2003.

ESPOSITO, R. Immunitas: protezione e negazione della vita. Torino: Einaudi, 2002.

FOUCAULT, M. Le jeu de Michel Foucault. In: .Dits et écrits: 1976-1979, Paris: Gallimard, 2001. v. 3. p. 299-300.

FOUCAULT, M. Bisogna difendere la società: corso al collège de France (1975- 1976). Milano: Feltrinelli, 1998.

GALLI, C. La guerra globale. Roma-Bari: Laterza, 2002. 
GIORGI, R. de. Il diritto nella società del rischio. In: . Temi di filosofia del diritto. Lecce: Pensa MultiMedia, 2006a. p. 69-81.

GIORGI, R. de. Diritto e reato nel secolo XXI. In: . Temi di filosofia del diritto. Lecce: Pensa MultiMedia, 2006b. p. 83-96.

KOSELLECK, R. Crisi. In: . Il vocabolario della modernità. Bologna: il Mulino, 2009. p. 95-109.

KOTEK, J.; RIGOÙLOT P. Il secolo dei campi: Detenzione, concentramento e sterminio: la tragedia del novecento. Milano: Mondadori, 2002.

LÖWY, M. Redenzione e utopia: figure della cultura ebraica mitteleuropea. Torino: Bollati Boringhieri, 1992. p. 105-135.

LUHMANN, N. Soziale System: Grundriss einer allgemeinen Theorie. Frankfurt: Suhrkamp, 1984.

NEAL, A. Exceptionalism and the politics of counter terrorism: liberty, security and thewar onterror. London: Routlage, 2009.

NUZZO, L. Le anticamere del diritto: Ordine politico ed eclissi della forma giuridica. Lecce: Pensa MultiMedia, 2008.

RESTA, E. La regola dell'emergenza. In Antigone, I, 2006. pp. 24-35.

RESTA, E. Diritto vivente. Roma-Bari: Laterza, 2008.

SCHMITT, C. Teologia politica: quattro capitoli sulla dottrina della sovranità. In:

Le categorie del politico. Bologna: Il Mulino, 1998. p. 29-89.

SCHMITT, C. Il concetto di politico. In: . Le categorie del politico. Bologna: Il Mulino, 1998. p. 101-167.

SCHMITT, C. Stato, movimento, popolo. In: . Un giurista davanti a se stesso: saggi e interviste. Vicenza: Neri Pozza Editore, 2005. p. 255-312.

STEYN, J. Guantánamo bay: the legal black hole. International and Comparative Law Quarterly, v. 52, n. 1, p. 25-41, 2004.

TRAVERSO, E. A ferro e fuoco: la guerra civile europea 1915-1945. Bologna: Il Mulino, 2007. WITTEGENSTEIN, L. Della certezza. Torino: Einaudi, 1978.

1 GALLI, C. La guerra globale. Roma-Bari: Laterza, 2002.

2 DAL LAGO, A. Polizia globale: guerra e conflitti dopo l'11 settembre. Verona: Ombre Corte, 2003.

3 FOUCAULT, M. Bisogna difendere la società. Corso al collège de France (1975- 1976). Milano: Feltrinelli, 1998. p. 29.

4 FOUCAULT, M. Le jeu de Michel Foucault. In: .Dits et écrits: 1976-1979. Paris: Gallimard, 2001. v. 3. p. 299-300. 
5 Sobre os aspectos temporais da observação, ver De Giorgi, 2006, p. 223-233; sobre o estado de direito, ver o mesmo De Giorgi, 2006, p. 213-222. Uma análise histórica e teórica do estado de direito se encontra nos ensaios fundamentais de Zolo, 2002, p. 17-88 e Costa, 2002, p. 89-170.

6 Authorization for Use of Military Force. Public Law, n. 107-40, 115 Stat. 224, 2001. Disponível em: <https://www. congress.gov/107/plaws/pub140/PLAW-107publ40.pdf>. Acesso em: 14 jun. 2017.

7 STEYN, J. Guantánamo bay: the legal black hole. International and Comparative Law Quarterly, v. 52, n. 1, p. 25-41, 2004.

8 LUHMANN, N. Soziale System: grundriss einen allgemeinen theorie. Frankfurt: Suhrkamp, 1984. p. 654.

9 BUTLER, J. Precaroius life: the powers of mourning and violence. London: Verso, 2004 p. 50-100.

10 WITTEGENSTEIN, L. Della certezza. Torino: Einaudi, 1978.

11 NEAL, A. Exceptionalism and the politics of counter terrorism: liberty, security and thewar onterror. London: Routlage, 2009.

12 SCHMITT, C. Teologia politica: quattro capitoli sulla dottrina della sovranità. In: tico. Bologna: Il Mulino, 1998. p. 29-89. p. 34.

13 DERRIDA, J. Forza di legge: il fondamento mistico dell'autorità. Torino: Bollati Boringhieri, 2003.

14 No sentido de «that the USA is an exception to the rule, that it need pay heed to international law or norms» tanto quanto no de «that it (USA) fears or expects no serious sacntion» (A. Neal 2009).

15 SCHMITT, C. Il concetto di politico. In: . Le categorie del politico. Bologna: Il Mulino, 1998. p. 101-167.

16 KOSELLECK, R. Crisi. In: Il vocabolario della modernità. Bologna: il Mulino, 2009. p. 95-109.

17 RESTA, E. La regola dell'emergenza. Antigone, I, p. 24-35, 2006. p. 29.

18 RESTA, E. Diritto vivente. Roma-Bari: Laterza, 2008.

19 BOLZ, N. Charisma und Souveranität: Carl Schmitt und Walter Benjamin im Schatten Max Webers. In: TAUBES, Jacob. Religionstheorie und Politische Teologie: Der Fürst dieser Welt - Carl Schmitt und die Folgen. München: Fink, 1983. v. 1. p. 254-257.

20 LÖWY, M. Redenzione e utopia: figure della cultura ebraica mitteleuropea. Torino: Bollati Boringhieri, 1992. p. 105-135.

21 BENJAMIN, W. Sobre o conceito da historia. In: BENJAMIN, Walter. O anjo da historia. Rio de Janeiro: Autentica, 2012, p. 59-61.

22 Sobre isso s ler a interesante análise de Roberto Esposito in: ESPOSITO, R. Immunitas: protezione e negazione della vita. Torino: Einaudi, 2002. p. 34-40.

23 AGAMBEN, G. Estado de exceção: homo sacer, II. São Paolo: Boitempo, 2004. p. 85.

24 TRAVERSO, E. A ferro e fuoco: la guerra civile europea 1915-1945. Bologna: Il Mulino, 2007. p. 191-197.

25 AGAMBEN, G. Estado de exceção: homo sacer, II. São Paolo: Boitempo, 2004. p. 96.

26 AGAMBEN, G. Estado de exceção: homo sacer, II. São Paolo: Boitempo, 2004. p. 88.

27 AGAMBEN, G. Estado de exceção: homo sacer, II. São Paolo: Boitempo, 2004. p. 89.

28 BUCI-GLUCKSMANN, C. H. Walter Benjamin et l'ange de l'histoire: une archéologie de la modernité. L'Ecrit du Temps 2, n. 2, p. 45-85, 1983. p. 67.

29 SCHMITT, C. Stato, movimento, popolo. In: Neri Pozza Editore, 2005. p. 255-312. p. 256.

30 p. 9-20.p. 13.

31 BENJAMIN, W. Sobre o conceito da historia. In: BENJAMIN, Walter. O anjo da historia. Rio de Janeiro: Autentica, 2012. p. 9-20. p. 13.

32 AGAMBEN, G. Infanzia e storia: distruzione dell'esperienza e origine della storia. Torino: Einaudi, 2001. p. 108.

33 AGAMBEN, G. Infanzia e storia: distruzione dell'esperienza e origine della storia. Torino: Einaudi, 2001, p. 108.

34 FOUCAULT, M. Bisogna difendere la società: corso al collège de France (1975- 1976). Milano: Feltrinelli, 1998.

35 ARENDT, H. Origens do totalitarismo. São Paolo: Companhia de Bolso, 2015. p. 391.

36 FOUCAULT, M. Bisogna difendere la società: corso al collège de France (1975- 1976). Milano: Feltrinelli, 1998. p. 165.

37 BATAILLE, G. La sovranità. Bologna: Il Mulino, 1990. p. 66.

38 AGAMBEN, G. Homo Sacer: o poder soberano e a vida nua. Belo Horizonte: Editora UFMG, 2007.

39 AGAMBEN, G. Estado de exceção: homo sacer, II. São Paolo: Boitempo, 2004.

40 AGAMBEN, G. Homo Sacer: o poder soberano e a vida nua. Belo Horizonte: Editora UFMG, 2007. p. 14. 
41 AGAMBEN, G. Homo Sacer: o poder soberano e a vida nua. Belo Horizonte: Editora UFMG, 2007. p. 35.

42 AGAMBEN, G. Homo Sacer: o poder soberano e a vida nua. Belo Horizonte: Editora UFMG, 2007. p. 173.

43 AGAMBEN, G. Che cosa è un campo. In: Mezzi senza fine. Torino: Bollati Boringhieri, 1996. p. 35-45. p. 37.

44 AGAMBEN, G. Homo Sacer: o poder soberano e a vida nua. Belo Horizonte: Editora UFMG, 2007. p. 177.

45 AGAMBEN, G. Homo Sacer: o poder soberano e a vida nua. Belo Horizonte: Editora UFMG, 2007.

46 KOTEK, J.; RIGOÙLOT P. Il secolo dei campi: Detenzione, concentramento e sterminio: la tragedia del novecento. Milano: Mondadori, 2002. p. 9.

47 GIORGI, R. de. Il diritto nella società del rischio. In: Media, 2006a. p. 69-81.

48 GIORGI, R. de. Diritto e reato nel secolo XXI. In: Temi di filosofia del diritto. Lecce: Pensa Multi2006b. p. 83-96.

49 NUZZO, L. Le anticamere del diritto: ordine politico ed eclissi della forma giuridica. Lecce: Pensa MultiMedia, 2008.

50 DERRIDA, J. Forza di legge: il fondamento mistico dell'autorità. Torino: Bollati Boringhieri, 2003.

\title{
EXCEPTION AS A GOVERNMENT RESOURCE
}

\begin{abstract}
Through the discussion of the ideas of Carl Schmitt and Walter Benjamin, Michel Foucault and Giorgio Agamben, this article aims at analyzing the workings of a government resource that uses exception as the norm. This resource is defined as "sovereign exceptionalism" and introduces new forms of control, that result from a combination that was previously unheard of between exceptionalism and governability in which the Law and democratic institutions continue to exist, but they are always emptier, revoked through governmental praxis. Sovereign exceptionalism ultimately reveals the paradox of the Law and radically deconstructs the modern political geometry and the reason that built its tenet.
\end{abstract}

Keywords: Crisis. Sovereignty. Biopower.

Submetido: 7 jun. 2017

Artigo convidado 